\title{
BIOLOGICAL TREATMENTS IN ALLERGY: PRESCRIPTION AND MANAGEMENT OF HYPERSENSITIVITY REACTIONS
}

Leyla Barakat ${ }^{1}$, María José Torres², Elizabeth J. Phillips ${ }^{3}$, Marco Caminati ${ }^{4}$, Yoon-Seok Chang $^{5}$, Davide Caimmi ${ }^{6}$, Mario Sanchez-Borges ${ }^{7}$, Lanny Rosenwasser ${ }^{8}$, Alain Didier ${ }^{9}$, Frédéric De Blay ${ }^{10}$, Jean-François fontaine ${ }^{11}$, Isabelle Bosse ${ }^{11}$, Sébastien lefevre ${ }^{12}$, Cintia Bassani $^{13}$, Maria di Filippo ${ }^{14}$, Ignacio J Ansotegui ${ }^{15}$, Mário Morais-Almeida ${ }^{16}$, Motohiro Ebisawa $^{17}$, Bryan Martin ${ }^{18}$, Bernard Thong ${ }^{19}$, Pascal Demoly ${ }^{20}$, and LUCIANA TANNO ${ }^{21}$

${ }^{1}$ University Hospital Centre Montpellier

${ }^{2}$ Universidad de Málaga Facultad de Medicina

${ }^{3}$ Vanderbilt University School of Medicine

${ }^{4}$ Verona University Hospital

${ }^{5}$ Seoul National University Bundang Hospital

${ }^{6}$ Department of respiratory medicine and allergy, Hôpital Arnaud de Villeneuve, CHU

Montpellier, Univ Montpellier

${ }^{7}$ Centro Medico-Docente La Trinidad

${ }^{8}$ Children's Mercy Hospitals and Clinics

${ }^{9} \mathrm{CHU}$ Toulouse

${ }^{10}$ University Hospital Strasbourg

${ }^{11}$ Allergist

${ }^{12}$ Universite de Lorraine

${ }^{13}$ IMED School of Medicine

${ }^{14}$ University of Pavia

${ }^{15}$ Hospital Quironsalud Bizkaia

${ }^{16}$ CUF-Descobertas Hospital

${ }^{17}$ National Hospital Organization, Sagamihara National Hospital

${ }^{18}$ Columbus State University

${ }^{19}$ Tan Tock Seng Hospital

${ }^{20}$ University Hospital of Montpellier

${ }^{21}$ Hospital Sírio Libanês

August 3, 2020

\begin{abstract}
Background: Allergy is witnessing major advances, in particular with the advent of biological therapies for treating allergic diseases. Given the novelty of these therapeutics, we aimed to explore by a worldwide survey, the prescription and the management of hypersensitivity reactions (HR) of biological agents (BA) in Allergy. Method: We built up an anonymous online questionnaire, sent out by mail and social media and circulated for 40 days. Results: 348 responses were from 59 countries, with a majority from Europe (62.6\%). 97\% of responders practiced allergy and 48.5\%, exclusively so. Allergy was mentioned as a full specialty in $69.5 \%$ of cases. $71 \%$ of responders confirmed the right of prescription of BA for allergists in
\end{abstract}


their country and $78.4 \%$ prescribed BA in their clinical practice. Europe included almost all the allergists who did not have the right of prescribing BA (95.5\%), specifically France (91\%). The most prescribed BA were Anti IgE (78.1\%) and anti IL5 (43.9\%). The most declared HR to BA were local reactions $(74.1 \%)$ followed by anaphylaxis like symptoms $(6.8 \%)$ and delayed exanthemas (5.1\%). Desensitization was considered in $18.9 \%$ of cases. These HR were reported in $48.8 \%$ of cases. Conclusion: Although BA are now a pillar in the treatment of allergic diseases and allergists are familiar with management of HR associated

with BA, their prescription is not authorized for allergists in all countries. BA showed to be generally safe but HR, which may be severe, could occur with a lack of consensus on the management.

\section{Hosted file}

29.07.20 P22 .doc available at https://authorea.com/users/348267/articles/473699-biologicaltreatments-in-allergy-prescription-and-management-of-hypersensitivity-reactions 